\title{
Adiposity and Insulin Sensitivity Derived from Intravenous Glucose Tolerance Tests in Antipsychotic-Treated Patients
}

\author{
Dan W Haupt*,', Peter A Fahnestock', Karen A Flavin', Julie A Schweiger', Angela Stevens', \\ Martha J Hessler', Justin Maeda', Michael Yingling and John W Newcomer' \\ 'Department of Psychiatry, Washington University School of Medicine, St Louis, MO, USA
}

\begin{abstract}
Cardiovascular disease is more common in schizophrenia patients than in the general population, with a hypothesized contribution from increases in adiposity produced by antipsychotic medications. We sought to test the relationship between adiposity and insulin resistance using frequently sampled intravenous glucose tolerance tests (FSIVGTTs) to quantify whole-body insulin sensitivity in chronically treated patients with schizophrenia or schizoaffective disorder and untreated healthy controls. FSIVGTTs, body mass index (BMI), and waist circumference were obtained in nondiabetic patients $(n=63)$ receiving olanzapine, risperidone, ziprasidone, or first generation antipsychotics, as well as in healthy controls $(n=14)$. Subject groups (including untreated healthy controls) were matched for BMI and all treated patient groups were additionally matched for age. Bergman's minimal model (MinMod) was used to calculate insulin sensitivity $\left(S_{1}\right)$, as well as secondary measures of interest. BMI and waist circumference significantly predicted insulin sensitivity measured as MinMod $S_{I}(F(I, 62)=35.1 I, p<0.000 I$ and $F(I, 46)=24.48, p<0.000 I$, respectively). In addition, BMI and waist circumference significantly predicted the acute plasma insulin response to the glucose challenge (AIR $)$, consistent with a $\beta$ cell compensatory response to insulin resistance (MinMod AIR $\mathrm{F}(1,65)=22.42, p<0.0001$ and $F(1,49)=11.72, p=0.0013$, respectively). Adiposity levels occurring during antipsychotic treatment are strongly related to insulin resistance, confirming that antipsychotic-induced weight gain can contribute to increased cardiometabolic risk in this population.

Neuropsychopharmacology (2007) 32, 256 I-2569; doi:I0.1038/sj.npp. I301392; published online 2I March 2007
\end{abstract}

Keywords: obesity; insulin resistance; diabetes; cardiovascular risk; schizophrenia; antipsychotics

\section{INTRODUCTION}

Patients with schizophrenia have a $20 \%$ shorter lifespan than the general population and a $50 \%$ increased risk of death from medical causes (Harris and Barraclough, 1998). Cardiovascular disease is the main contributor to medical morbidity and mortality in the general population, and patients with schizophrenia are 2.3 times more likely to die from cardiovascular disease than the general population (Osby et al, 2000). Key modifiable risk factors for cardiovascular disease (insulin resistance, smoking, obesity, hypercholesterolemia, hypertension, inactivity, and hyperglycemia) are more prevalent in patients with schizophrenia than in the general population (Allebeck, 1989; Allison et al, 1999; Dixon et al, 1999; Herran et al, 2000; Davidson et al, 2001; Davidson, 2002). Treatment with antipsychotic medications has been associated with increases in weight and other cardiometabolic risk factors (American Diabetes

\footnotetext{
*Correspondence: Dr DW Haupt, Department of Psychiatry, Washington University School of Medicine, Box 8134, 660 S. Euclid, St Louis, MO 63। I0-1093, USA, Tel: + I 314362 2465; Fax: + I 314 362 2025, E-mail: hauptd@wustl.edu

Received 7 November 2006; revised 26 January 2007; accepted 13 February 2007
}

Association, 2004; Casey et al, 2004; Newcomer, 2005; Haupt, 2006). Weight gain during antipsychotic treatment consists primarily of adiposity (Zhang et al, 2004; Graham et al, 2005) and increased adiposity is an established risk factor for diabetes and cardiovascular disease in the general population (Peiris et al, 1989; Koh-Banerjee et al, 2004).

One way to understand the contribution of antipsychotic medications to the risk for developing diabetes and cardiovascular disease is to examine the relationship between adiposity and insulin sensitivity. Although antipsychotic-induced increases in adiposity are a key hypothesized mechanism for antipsychotic-associated increases in the risk of diabetes, reports of adiposity-independent effects of medications (Houseknecht et al, 2007) and lack of consistent correlation between weight change and plasma glucose in short-term clinical trials (Meyer, 2002; Lindenmayer et al, 2003; Simpson et al, 2004) have led to uncertainty regarding the importance of weight gain in contributing to changes in glucose metabolism during antipsychotic treatment. Specifically regarding the relationship of weight gain to the risk of diabetes, questions have been raised about the applicability of general population data to antipsychotic-treated patients with schizophrenia (Boehm et al, 2004). The hypothesis that increases in adiposity are a risk factor for diabetes in the general 
population but are not related to the risk of diabetes during antipsychotic treatment suggests that there may not be a significant relationship between adiposity and insulin sensitivity in antipsychotic-treated patients. Although this alternate hypothesis seems less likely given the established relationship between adiposity and insulin resistance in nonpsychiatric samples, and the increased prevalence of diabetes and cardiovascular disease in treated psychiatric populations, the relationship between adiposity and insulin sensitivity is readily testable in treated psychiatric patients.

The sensitivity of techniques used to detect variation in insulin sensitivity is an important consideration in study design and interpretation. Frequently sampled intravenous glucose tolerance tests (FSIVGTT) provide measures of insulin sensitivity and $\beta$ cell function in a single 3-h session. The FSIVGTT is useful because of its greater sensitivity compared with the fasting measures, and its significantly lower cost and complexity than the gold-standard hyperinsulinemic euglycemic clamp procedure. The FSIVGTT is more complicated with respect to data collection and interpretation than fasting assessments or a standard oral glucose tolerance test, but can be useful in research settings. Intravenous rather than oral administration of glucose avoids the variability seen in glucose-absorption rates through the gastrointestinal tract. Insulin sensitivity, as assessed by FSIVGTT, is significantly related to adiposity in studies of healthy human samples (Welch et al, 1990; Mayer-Davis et al, 1997). Using body mass index (BMI) or computed tomography as indicators of adiposity, adiposity has been reported to account for $23 \%$ (Karter et al, 1996) to $45 \%$ (Macor et al, 1997) of the variance in insulin sensitivity as measured by FSIVGTT in nonpsychiatric samples.

This study aimed to test the relationship between adiposity, measured as BMI or waist circumference, and a FSIVGTT-derived measure of insulin sensitivity, hypothesizing a significant association, similar to what has been reported in untreated, nonpsychiatric healthy human and healthy animal subjects. BMI and waist circumference were used as indirect measurements of adiposity; these measures (1) are readily available clinically, with BMI especially offering high test-retest reliability (Reaven, 2005); (2) are well-correlated with direct measurements of adiposity (Janssen et al, 2002); and (3) have predictive validity as indicators of insulin sensitivity even in clinical trial sized samples (McLaughlin et al, 2003). The secondary aims of this study were (1) to evaluate the relationship between adiposity and acute insulin response to glucose loading and
(2) to evaluate adiposity-independent effects of antipsychotic treatment and psychiatric diagnosis on insulin sensitivity and secretion in BMI-matched treatment groups. Whereas different antipsychotic medications can induce different amounts of change in body weight and adiposity during prospective treatment (American Diabetes Association, 2004; Newcomer, 2005), differences in adiposity that emerge during treatment can complicate the assessment of adiposity-independent effects, leading this study and others to match treatment groups for adiposity to better test for adiposity-independent medication effects.

\section{METHODS}

\section{Subjects}

Sixty-three nondiabetic patients with schizophrenia and 16 control subjects participated after giving written informed consent. Studies were approved by the Institutional Review Boards for Washington University School of Medicine (WUSM) and the Missouri Department of Mental Health. Chronically treated patients with DSM-IV schizophrenia or schizoaffective disorder, aged 18-60 years, were recruited for study participation. Patients were required to have been receiving treatment with olanzapine $(n=24)$, risperidone $(n=16)$, ziprasidone $(n=11)$, or first-generation antipsychotics $(n=12)$ (Table 1$)$, with no greater than $25 \%$ changes in antipsychotic dose over the 3 months before study entry. Duration of prior treatment ranged from $\geqslant 24$ to $\geqslant 3$ months ( 21 subjects $\geqslant 24$ months, 8 subjects $18-24$ months, 10 subjects $12-18$ months, 10 subjects $6-12$ months, 14 subjects 3-6 months), with a similar distribution of treatment duration for each of the treated subject groups, and no difference in mean duration of exposure $(\mathrm{F}(3,33)=1.51, p=0.23)$. No medication changes of any kind were permitted for 2 weeks before, or during, the period of study participation. Patients were recruited through outpatient clinics associated with Washington University School of Medicine. Healthy control subjects $(n=14)$ were recruited through advertising.

Antipsychotic treatment groups were matched for BMI and age, using a method similar to that used in a previous study from our group, (Newcomer et al, 2002) excluding more obese or more or less aged subjects that might otherwise have been consecutively enrolled into specific treatment groups to maintain group matching. Whereas patients tended to have higher BMI and older age in

Table I Descriptive Statistics (Mean $\pm S D$, Frequency Distribution) for Treated Schizophrenia $(n=63)$ and Untreated Healthy Control $(n=16)$ Subjects

\begin{tabular}{lcccccrc}
\hline Subject group & Age & BMI & $\begin{array}{c}\text { Ethnicity white/African } \\
\text { American/unknown }\end{array}$ & Sex M/F & $\begin{array}{c}\text { Pack(s) of cigarettes } \\
\text { smoked per day }\end{array}$ & $\begin{array}{c}\text { BPRS total } \\
\text { score }\end{array}$ & Dose \\
\hline Controls $(n=\mid 4)$ & $31.29 \pm 9.00$ & $27.65 \pm 3.80$ & $12 / 2 / 0$ & $10 / 4$ & $0.02 \pm 0.08$ & - \\
Risperidone $(n=16)$ & $43.13 \pm 12.41$ & $30.52 \pm 6.58$ & $6 / 10 / 0$ & $13 / 3$ & $0.72 \pm 0.41$ & $26.13 \pm 5.01$ & $5.44 \pm 2.85$ \\
Olanzapine $(n=24)$ & $39.17 \pm 8.62$ & $32.13 \pm 4.97$ & $7 / 16 / 1$ & $17 / 7$ & $0.86 \pm 0.65$ & $28.44 \pm 6.76$ & $19.69 \pm 10.49$ \\
First generation $(n=\mid 2)$ & $38.75 \pm 7.16$ & $30.60 \pm 6.55$ & $3 / 9 / 0$ & $1 / / 1$ & $0.60 \pm 0.56$ & $27.64 \pm 6.14$ & $29.12 \pm 22.87$ \\
Ziprasidone $(n=\mid 1)$ & $36.82 \pm 9.03$ & $28.73 \pm 6.03$ & $6 / 5 / 0$ & $7 / 4$ & $0.67 \pm 0.72$ & $31.09 \pm 6.06 \quad 165.46 \pm 65.78$ \\
\hline
\end{tabular}

Abbreviations: BMI, body mass index; BPRS, brief psychiatric rating scale. 
comparison to controls, BMI matching was maintained across all treated patient groups, and more broadly across all subject groups (including treated patients and untreated healthy controls) (main effect of group on BMI: $\mathrm{F}(4,72)=1.67, p=0.17)$. Subject groups were not ideally matched for age (main effect of group on age: $\mathrm{F}(4,72)=3.08, p=0.021$ ), explained by a slightly younger untreated healthy control group, with the treated patient groups well-matched for age $(\mathrm{F}(3,59)=1.08, p=0.36)$.

All subjects underwent a medical screening and diagnostic evaluation, including the Diagnostic Interview for Genetic Studies (Nurnberger et al, 1994) (DIGS) and a review of available medical records, with a final research diagnosis made by a research psychiatrist using Diagnostic and Statistical Manual of Mental Disorders, Fourth Edition (American Psychiatric Association, 1994) algorithms. Subjects were additionally excluded for (1) Axis I disorders except schizophrenia or schizoaffective disorder, and substance abuse and/or dependence occurring more than 6 months before the study entry; (2) medical conditions that could confound metabolic assessments, including history of diabetes mellitus, recognized cardiovascular and respiratory conditions with hemodynamic compromise or hypoxia, malignancy, epilepsy, endocrine disease (excluding corrected, stable thyroid abnormalities), fever, dehydration, nausea, body weight less than $80 \%$ of ideal, pregnancy or high-dose estrogen therapy, narcotic, oral corticosteroid or spironolactone therapy, or sedative hypnotic withdrawal. Similarly, no subjects treated with glucose- or lipidlowering medications were included for analysis. Subjects were excluded for type 1 and type 2 diabetes mellitus as determined by a random glucose of $\geqslant 200$ and/or a fasting glucose of $\geqslant 140 \mathrm{mg} / \mathrm{dl}$ (World Health Organization, 1985) based on diagnostic criteria in use at the time of study initiation. All patients were additionally characterized using the Brief Psychiatric Rating Scale (Overall, 1974) (BPRS; 18-item, 1-7 scale).

Baseline clinical data as well as mean doses of the primary antipsychotic treatments for each treated patient group are listed in Table 1. Twelve of the 63 patients were receiving first-generation antipsychotics. Of these 12 patients, two were receiving an oral agent only (one haloperidol $10 \mathrm{mg}$ / day, one thiothixene $5 \mathrm{mg} /$ day), six were receiving haloperidol decanoate as their only antipsychotic treatment (mean $\mathrm{mg} / \mathrm{month}=272.22 \pm 188.76)$, three were receiving fluphenazine decanoate as their only antipsychotic treatment (mean $\mathrm{mg} / \mathrm{month}=52.78 \pm 41.11$ ), and one was receiving $10 \mathrm{mg}$ oral haloperidol/day plus $150 \mathrm{mg}$ haloperidol decanoate every month. Mean antipsychotic dose for firstgeneration oral agents (in haloperidol equivalents) is listed in Table 1. Additionally, six patients in this group were receiving an anticholinergic medication (benztropine mesylate, mean daily $\mathrm{mg} \pm \mathrm{SD}=2.67 \pm 1.03$ ).

Twenty-four of the 63 patients were receiving olanzapine (Table 1). Of these 24, seven were receiving adjunctive first-generation antipsychotics (one receiving fluphenazine decanoate $50 \mathrm{mg}$ every 2 weeks, one receiving trifluoperazine $10 \mathrm{mg} /$ day, one receiving haloperidol $20 \mathrm{mg} / \mathrm{day}$, four receiving haloperidol deconoate mean $\mathrm{mg} /$ month $=183.33 \pm 102.74)$. Six patients were receiving benztropine mesylate, mean dose $2.5 \pm 1.22 \mathrm{mg} /$ day. Three patients were receiving mood stabilizers: valproate
$1500 \mathrm{mg} /$ day, lamotrigine $450 \mathrm{mg} / \mathrm{day}$, and gabapentin $1800 \mathrm{mg} /$ day.

Sixteen of the 63 patients were receiving risperidone (Table 1). Of those 16, two were receiving anticholinergics (benztropine mesylate mean daily $\mathrm{mg} \pm \mathrm{SD}=1.5 \pm 0.71$ ). In addition, one patient was receiving adjunctive haloperidol decanoate $200 \mathrm{mg}$ every 2-3 weeks, one was receiving lithium $600 \mathrm{mg} /$ day, and one was receiving valproate $1500 \mathrm{mg} / \mathrm{day}$.

Eleven of the 63 patients were receiving ziprasidone (Table 1). Of those 11, four were receiving anticholinergics (three benztropine mesylate mean daily $\mathrm{mg} \pm \mathrm{SD}=$ $2.83 \pm 1.89$, one trihexyphenidyl $1 \mathrm{mg} /$ day). In addition, one patient was receiving adjunctive haloperidol decanoate $100 \mathrm{mg} / \mathrm{month}$, and two patients were receiving valproate $750 \mathrm{mg} /$ day.

Of all 63 treated subjects, nine were receiving benzodiazepines, two were receiving zolpidem, seven were receiving antidepressants, eight were receiving antihypertensive medications, and one was receiving conjugated estrogens $0.625 \mathrm{mg} / \mathrm{med}$ roxyprogesterone $2.5 \mathrm{mg}$ daily.

\section{Procedure}

This study used the well-characterized modified FSIVGTT procedure (Ader et al, 1985; Beard et al, 1986; Bergman et al, 1987; Bergman, 1989; Welch et al, 1990; Steil et al, 1993) including frequent plasma sampling and a glucose challenge followed by an insulin challenge (Welch et al, 1990) in combination with a computerized mathematical model (Bergman's minimal model, or MinMod), to generate measures of insulin secretion $\left(\mathrm{AIR}_{\mathrm{G}}\right)$ and insulin sensitivity $\left(S_{\mathrm{I}}\right)$ (Matthews et al, 1985; Haffner et al, 1996; Hermans et al, 1999a, b). Intravenous infusion of glucose is followed by intravenous infusion of insulin, with frequent blood sampling (details below). The resulting data are analyzed by MinMod, which assumes that (1) glucose inhibits its own production, and increases its own utilization proportional to its plasma concentration, (2) that insulin acts synergistically with glucose to promote these effects, and (3) the effects of insulin are proportional to its concentration in a compartment separate from plasma. The software uses these assumptions to adjust the values of the differential equations that describe the model until the recorded pattern of plasma glucose values is fitted (Bergman, 1989).

The homeostasis model assessment (HOMA) was used secondarily to calculate an index of insulin resistance (HOMA IR) using the formula HOMA IR = (fasting insulin $(\mu \mathrm{U} / \mathrm{ml}) \times$ fasting glucose $(\mathrm{mmol} / \mathrm{l})) / 22.5$ (Matthews et al, 1985).

Subjects consumed a standardized diet providing $30 \mathrm{kcal} / \mathrm{kg}$ body weight/day (50\% carbohydrate and $33 \%$ fat), provided to them by Washington University General Clinical Research Center (GCRC) dietary resources, for 3 days before each study day. There was a small but statistically significant difference in average daily calories consumed across subject groups $(\mathrm{F}(4,70)=2.85, p=0.03)$ ranging from $2033 \mathrm{kcal} /$ day consumed by the ziprasidone group to $2488.5 \mathrm{kcal} /$ day consumed by the control group (Table 2). However, when the diets were separated into carbohydrates, fat, and protein for more in-depth analyses, there were no significant differences between subject groups 
Table 2 Dietary Composition (Mean \pm SD) for Treated Schizophrenia $(n=61)$ and Untreated Healthy Control $(n=\mid 4)$ Subjects

\begin{tabular}{lcccc}
\hline Treatment group & Mean daily kcal & Mean daily carbohydrates (kcal) & Mean daily fats (kcal) & Mean daily proteins (kcal) \\
\hline Risperidone $(n=16)$ & $2273.393 \pm 357.765$ & $981.461 \pm 392.5$ & $1186.412 \pm 914.784$ & $373.360 \pm 74.249$ \\
Olanzapine $(n=23)$ & $2368.174 \pm 285.601$ & $1020.879 \pm 428.460$ & $1273.762 \pm 884.518$ & $382.743 \pm 66.432$ \\
Control $(n=14)$ & $2488.488 \pm 308.764$ & $998.904 \pm 470.616$ & $1513.177 \pm 1093.665$ & $393.475 \pm 65.763$ \\
First generation $(n=12)$ & $2352.994 \pm 402.237$ & $1153.853 \pm 349.328$ & $904.612 \pm 662.622$ & $403.461 \pm 54.759$ \\
Ziprasidone $(n=10)$ & $2033.045 \pm 391.54 \mid$ & $992.617 \pm 300.349$ & $791.764 \pm 581.031$ & $350.178 \pm 68.113$ \\
\hline
\end{tabular}

in the average daily consumption of any of the three categories $(\mathrm{F}(4,70)=0.38, p=0.82 ; \mathrm{F}(4,70)=1.37, p=0.25$; and $\mathrm{F}(4,70)=1.05, p=0.39$; respectively).

At 0800 on the study days, after an $8-10 \mathrm{~h}$ overnight fast (except for water), two intravenous lines were inserted, one for infusion and the other for blood sampling, by the supervising physician and GCRC nursing personnel who were present throughout the session. Subjects were reclining at a roughly $45^{\circ}$ angle in bed, with one hand kept warm in a clear acrylic box thermostatically warmed to $50^{\circ} \mathrm{C}$ to arterialize the blood samples (obtained from Dr Dwight Matthews, University of Vermont, dmatthew@uvm.edu), which were drawn from an indwelling catheter in that hand or forearm. Infusions were made through the contralateral catheter. A bolus of regular human recombinant insulin $(0.03 \mathrm{U} / \mathrm{kg}$ ) was given at $20 \mathrm{~min}$ (Novo Nordisk Pharmaceuticals Inc., Princeton, NJ, USA). Blood samples to measure plasma glucose and insulin concentrations were drawn at $-15,-10,-5,2,4,8,19,22,30,40,50,60,70,80$, 100 , and $180 \mathrm{~min}$ after the start of the dextrose infusion. In addition, baseline $(-15,-10,-5 \mathrm{~min})$ preload fasting measures of C-peptide and glucagon were collected (an average of the three values was used for analysis). Our use of a modified FSIVGTT procedure with 16 sampling times was derived from previously reported FSIVGTT procedures with 12-33 sampling times (Bergman et al, 1981; Steil et al, 1993). MinMod is designed to accept a range of sample timepoints and sample frequencies in its calculation $S_{I}$ and $\mathrm{AIR}_{\mathrm{G}}$. From both a physiologic and mathematical modeling perspective, the most critical issue in the derivation of $S_{\mathrm{I}}$ is the accuracy and value of plasma glucose and insulin immediately following the 20-min exogenous insulin infusion. The number and frequency of samples at timepoints more distal to the insulin infusion have little effect on MinMod calculations. Our protocol allowed high-density sampling at the critical baseline and post-glucose and post-insulin infusion periods, with less frequent sampling at the end of the study where fewer data are needed to construct an accurate curve. A urine drug screen was administered to subjects with any relatively recent medical record documentation of substance abuse to confirm no active use.

Waist circumference was determined by placing a tape measure around the abdomen at the level of the iliac crest snugly without causing skin compression, parallel to the floor at the end of normal expiration (National Institutes of Health, 2000). BMI was calculated as the weight in kilograms divided by the square of the height in meters (National Institutes of Health, 2000).

\section{Data Analysis}

Analysis of covariance (ANCOVA) was used to test the hypotheses concerning main and interactive effects of adiposity (BMI or waist circumference) and subject group (group factor with five levels: risperidone, olanzapine, ziprasidone, first-generation antipsychotic, and control) on insulin sensitivity (MinMod $S_{\mathrm{I}}$ ). Secondary analyses tested these same effects on pancreatic $\beta$-cell function $\left(\right.$ MinMod $\left.\mathrm{AIR}_{\mathrm{G}}\right)$. Analysis of variance (ANOVA) was further used to test the secondary hypothesis concerning any main effect of subject group (group factor with five levels: risperidone, olanzapine, ziprasidone, first-generation antipsychotic, and control) on insulin sensitivity (MinMod $S_{\mathrm{I}}$ ). The overall significance level was set at $p=0.05$.

To ensure group comparability, ANOVA was used to test for an effect of subject group on either BMI or age. In addition to effects of BMI (Resnick et al, 1998) and age (Harris et al, 1998), variables such as ethnicity and smoking may also be associated with differences in insulin sensitivity (Resnick et al, 1998). As an additional precaution against confounders to the interpretation of the results, each of these variables was individually added as either a covariate term (ANCOVA) or factor to the main models.

\section{RESULTS}

Adiposity significantly predicted insulin sensitivity in treated patients and untreated healthy controls. Including all subject groups in the model (five groups: risperidone, olanzapine, typicals, ziprasidone, and untreated healthy controls) and adiposity as the covariate term (using BMI or waist circumference, respectively) in an ANCOVA model predicting insulin sensitivity, a main effect of adiposity was detected for MinMod $S_{\mathrm{I}}(\mathrm{F}(1,62)=35.11, p<0.0001$ and $\mathrm{F}(1,46)=24.48, p<0.0001$, respectively, see Figure 1). Consistent with previous results from nonpsychiatric human samples, BMI or waist circumference explained a third of the variance in $S_{\text {I }}$ in this sample. Similarly, adiposity significantly predicted the acute insulin secretory response to glucose challenge (MinMod $\mathrm{AIR}_{\mathrm{G}}$ ) in treated patients and untreated healthy controls. In a similar ANCOVA model, a main effect of adiposity (using BMI or waist circumference, respectively) was detected for MinMod $\operatorname{AIR}_{\mathrm{G}}(\mathrm{F}(1,65)=$ 22.42, $p<0.0001$ and $\mathrm{F}(1,49)=11.72, p=0.0013$, respectively, see Figure 2).

There were no consistent effects of medication group on either insulin sensitivity or secretion, independent of adiposity. This was indicated by the detection of no 

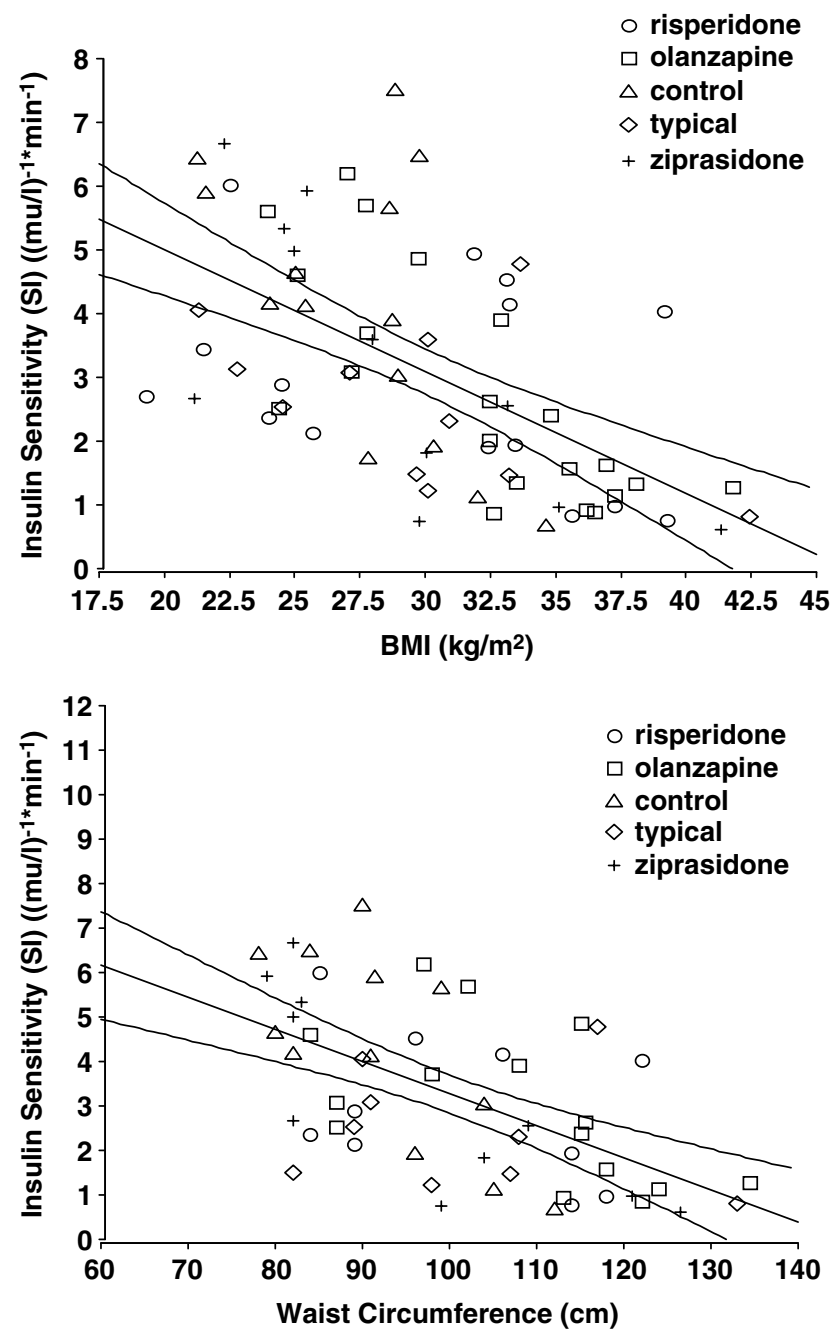

Figure I Insulin sensitivity $\left(S_{1}\right)$ calculated using MiniMod in healthy controls and treated schizophrenia patients as a function of BMI $\left(R^{2}=0.338\right)$ and waist circumference $\left(R^{2}=0.331\right)$, with regression lines and $95 \%$ confidence intervals displayed.

significant main effects or interactions of subject group on MinMod $S_{\mathrm{I}}(\mathrm{F}(4,46)=2.32, p=0.07)$ or MinMod $\mathrm{AIR}_{\mathrm{G}}$ $(\mathrm{F}(4,49)=0.23, p=0.92)$ in these ANCOVA models using waist circumference as an indicator of adiposity. Using BMI as the indicator of adiposity in those models, there were no interactions with subject group on either MinMod $\operatorname{AIR}_{G}$ or MinMod $S_{\mathrm{I}}$ and no main effect of subject group on MinMod $\operatorname{AIR}_{\mathrm{G}}(\mathrm{F}(4,65)=0.23, p=0.92)$. There was a main effect of subject group on MinMod $S_{\mathrm{I}}$ using BMI as the indicator of adiposity $(\mathrm{F}(4,62)=2.57, p=0.05)$, but Bonferroni-Dunn post hoc comparisons detected no significant differences in $S_{\text {I }}$ between any two individual subject groups.

In general, adiposity was also a predictor of measured values for other indices of glucose and lipid metabolism. A significant main effect of BMI or waist circumference, with no significant main effect of, or interaction with, subject group was detected on several variables. A main effect of BMI was detected for fasting triglyceride $(\mathrm{F}(1,65)=4.18$, $p=0.045)$, average fasting insulin $(\mathrm{F}(1,66)=44.04$, $p<0.0001)$, HOMA IR $(\mathrm{F}(1,66)=37.16, p<0.0001)$, and HOMA $\beta$ cell function $(\mathrm{F}(1,66)=39.96, p<0.0001)$. A main
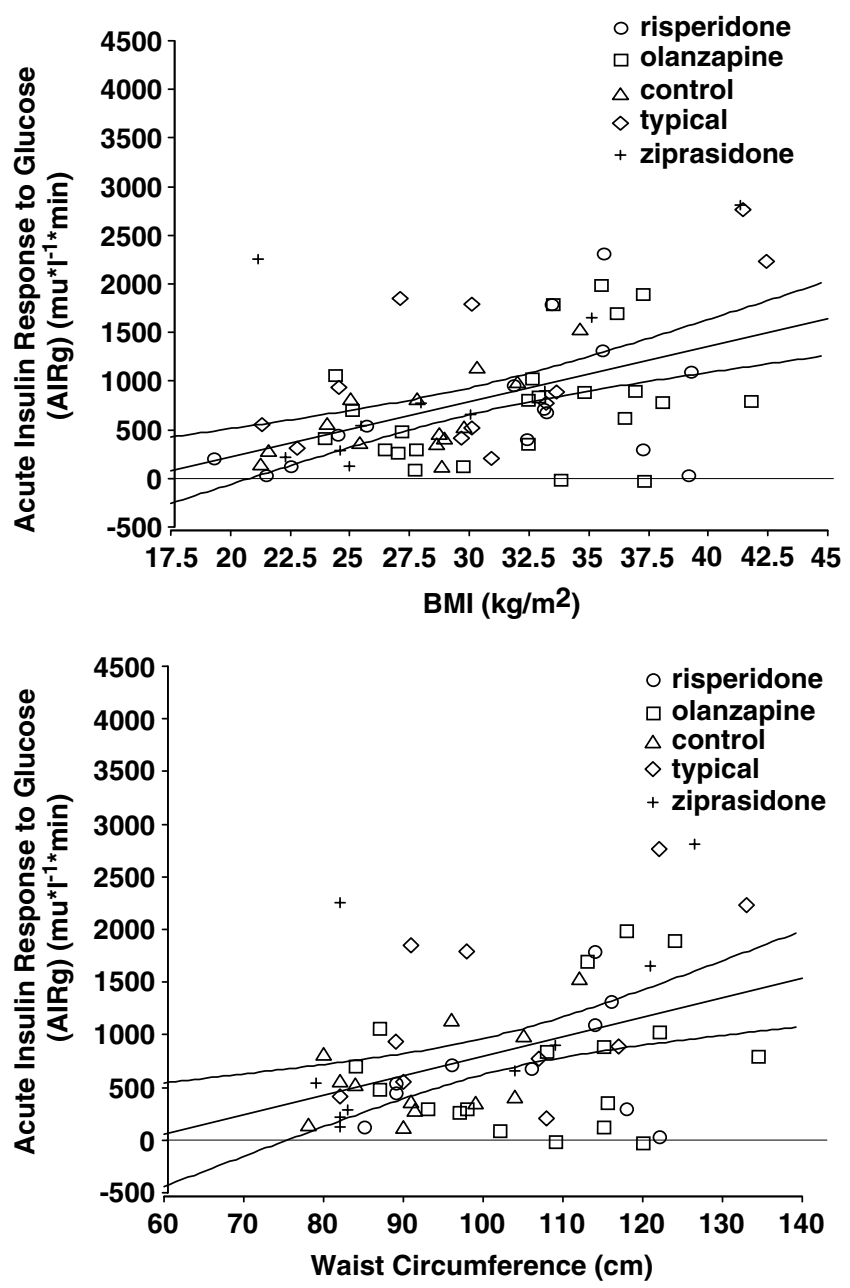

Figure 2 Acute insulin response $\left(A I R_{G}\right)$ to intravenous glucose administration in healthy controls and treated schizophrenia patients as a function of $\mathrm{BMI}\left(R^{2}=0.229\right)$ and waist circumference $\left(R^{2}=0.165\right)$, with regression lines and $95 \%$ confidence intervals displayed.

effect of waist circumference was detected for average fasting insulin $(\mathrm{F}(1,50)=34.64, p<0.0001)$, HOMA IR $(\mathrm{F}(1,50)=30.12, p<0.0001)$, and HOMA $\beta$ cell function $(\mathrm{F}(1,50)=31.99, p<0.0001)$. No significant effect of BMI or waist circumference on fasting plasma glucose was detected.

Exploratory analyses of other variables reported to be related to adiposity in nonpsychiatric populations also showed an effect of adiposity in treated subjects. A significant main effect of BMI on total cholesterol $(\mathrm{F}(1,67)=4.56, \quad p=0.037)$, average baseline C-peptide $(\mathrm{F}(1,67)=39.26, \quad p<0.0001), \quad$ and fasting glucagon $(\mathrm{F}(1,67)=7.19, p=0.0092)$ was detected, with no main effect of or interaction with subject group. A main effect of waist circumference on systolic blood pressure (BP) $(\mathrm{F}(1,51)=4.50, \quad p=0.039)$, diastolic $\mathrm{BP} \quad(\mathrm{F}(1,51)=5.00$, $p=0.0298)$, average baseline C-peptide $(\mathrm{F}(1,51)=40.96$, $p<0.0001)$, and fasting glucagon $(\mathrm{F}(1,51)=6.20$, $p=0.0161$ ) was detected, with no main effect of or interaction with subject group. There was a significant interaction between waist circumference and subject group in the prediction of diastolic $\mathrm{BP}(\mathrm{F}(4,51)=2.58, p=0.0482)$. 
The primary finding that adiposity, but not disease or medication condition, significantly contributes to the variance in insulin sensitivity and secretion was not altered by including in the model factors such as ethnicity, smoking status, or by including or excluding the subjects receiving concomitant medications, all of which might be hypothesized to confound the interpretation of results. In an ANCOVA model incorporating smoking status (ie current packs per day) and ethnicity, respectively, the main effect of BMI on MinMod $S_{\mathrm{I}}$ remained significant $(\mathrm{F}(1,52)=7.71$, $p=0.0076$ and $\mathrm{F}(1,51)=24.61, p=0.0001$, respectively), with no main effect of subject group $(\mathrm{F}(4,52)=0.66$, $p=0.62$ and $\mathrm{F}(4,51)=1.63, p=0.182$, respectively), no main effect of smoking status $(\mathrm{F}(1,52)=0.81, p=0.37)$ or ethnicity $(\mathrm{F}(1,51)=3.31, p=0.075)$, and no significant twoor three-way interactions involving BMI, subject group, and either ethnicity or smoking status. Similar results were found for MinMod $\mathrm{AIR}_{\mathrm{G}}$.

\section{Comments}

The primary result of this study using MinMod analysis of FSIVGTT data is that BMI and waist circumference significantly predict insulin sensitivity in antipsychotictreated patients with schizophrenia and schizoaffective disorder as well as in untreated healthy controls. These results extend previous studies that describe the association between adiposity and insulin sensitivity in nonpsychiatric subjects, indicating that this association is similarly observed in patients with schizophrenia and schizoaffective disorder treated with antipsychotic medications. The amount of variance in insulin sensitivity (33-34\%) that was explained by adiposity in this study is consistent with previous results from a variety of nonpsychiatric human subject samples; these results do not support the perspective that the relationship between adiposity and insulin sensitivity is fundamentally different in patients treated with antipsychotics as compared with untreated humans without psychiatric disease. Whereas patients' level of adiposity can certainly be a function of medication effects, additional nonadiposity-related medication effects or schizophrenia-related effects might add to or interact with the large effect of adiposity on these parameters. However, this study did not detect significant adiposity-independent effects (ie effects of medication group or disease group) on insulin sensitivity, or on the initial insulin response to glucose. These results strongly suggest that the effect of adiposity on insulin sensitivity in patients receiving antipsychotic treatment is relatively large as compared with adiposity-independent effects.

Some previous studies in antipsychotic-treated psychiatric patients have conducted post hoc or exploratory examinations of the relationship of weight or adiposity to measures of glucose metabolism, sometimes failing to detect a significant relationship between weight change and some indication of altered metabolism (Meyer, 2002; Lindenmayer et al, 2003; Simpson et al, 2004). Despite the limitations of some of these analyses, the results have prompted questions about the association between antipsychotic-related changes in weight or adiposity and risk for disturbances in glucose metabolism (Boehm et al, 2004). Failure to detect significant correlations involving weight and glucose metabolism in some previous studies may, in part, be related to the common use of fasting plasma glucose as the indicator of glucose metabolism. Changes in fasting plasma glucose in response to increasing insulin resistance are initially buffered by compensatory increases in insulin secretion that prevent hyperglycemia as long as pancreatic $\beta$ cell reserve remains available. Therefore, studies of relatively short duration in patients who still have reserve insulin secretory capacity would not be expected to observe changes in fasting plasma glucose despite adiposity-related increases in insulin resistance, whereas patient samples with limited $\beta$ cell reserve (eg, older subjects with an extended prior duration of insulin resistance) might manifest increases in fasting plasma glucose in relation to increased insulin resistance within short time frames. The current sample of patients is likely to be representative of many published schizophrenia samples. In the current study, a significant correlation was observed between adiposity and pancreatic $\beta$ cell insulin secretory response to glucose loading (measured as $\mathrm{AIR}_{\mathrm{G}}$ ), suggesting some degree of intact $\beta$ cell response to insulin resistance. Consistent with this, the current study found no correlation between adiposity and fasting plasma glucose. The use of a validated measure of insulin sensitivity in this study, instead of fasting glucose, allowed the demonstration of an important effect of adiposity on glucose metabolism. It should be noted that had this study used only fasting plasma glucose as a measure of glucose metabolism, it would have been unable to detect the deleterious effect of increasing adiposity.

The current study did not provide evidence that adiposity-independent effects of medications or psychiatric disease state make a significant contribution to insulin sensitivity or the acute insulin response to glucose. No significant effect of treatment group or interaction with treatment group (olanzapine, risperidone, ziprasidone, first-generation antipsychotics, and untreated healthy controls) on insulin sensitivity or acute insulin response was detected. It should be noted that the failure to detect an effect of treatment group on insulin sensitivity may be a type II error, and studies with similar sample size have, previously, detected such treatment group effects (Newcomer et al, 2002; Henderson et al, 2005). However, the 'adiposity-independent' effects of treatment group previously reported in these studies were detected when subjects were similarly matched for adiposity using BMI, which in some individuals or cohorts might fail to account for treatment group-related differences in intramuscular or abdominal fat; in this way, treatment group effects detected in those studies may actually be accounted for by treatment group-related differences in adiposity. In addition, unlike other studies, this study provided a dietary control for all subjects, reducing treatment group-related differences in total calorie and fat intake. This procedure may have obscured medication-related differences in food preference and calorie intake that might have contributed to the treatment group differences in insulin sensitivity observed in other studies. In any case, direct effects of antipsychotic medications on insulin sensitivity - ie those not mediated by adiposity - may be relatively small and more difficult to experimentally detect in comparison to the larger effects of adiposity on insulin sensitivity. 
The current findings are relevant to the prediction of risk for adverse health outcomes related to decreased insulin sensitivity. Decreases in insulin sensitivity are an important early event in the development of the insulin resistance syndrome (Reaven, 2005) and the metabolic syndrome (National Cholesterol Education Program, 2002), which are major risk factors for cardiovascular disease and type 2 diabetes mellitus. The predictive effect of adiposity in this study was found across all treatment conditions, including untreated healthy controls and all medication groups. The strong relationship between adiposity and insulin sensitivity is consistent with numerous prior reports of intravenous glucose tolerance testing in nonpsychiatric populations, (Welch et al, 1990; Karter et al, 1996; Macor et al, 1997; Mayer-Davis et al, 1997) and consistent with an emerging consensus regarding the importance of increased adiposity in psychiatric populations.

There were limitations to this study. Owing to the interest in matching for adiposity, which is not possible during prospective treatment with medications that have differential effects in this area, this study was not a prospective, randomized trial. Such trials including detailed measures of insulin sensitivity are underway, and will be useful for quantifying treatment-induced changes in adiposity and related treatment-induced changes in insulin sensitivity. The use of chronically treated, stable outpatients in this study, rather than more acutely ill inpatients, may not capture early treatment-induced changes in insulin sensitivity that could occur in advance of changes in adiposity (Houseknecht et al, 2007). However, the use of stable outpatients provides the benefit of minimizing potentially confounding metabolic effects of acute psychological stress, most notably acute elevations in plasma cortisol, which have been shown to affect insulin sensitivity and pancreatic $\beta$ cell function (Bjorntorp and Rosmond, 2000). On a related note, studies of acutely ill psychiatric populations may overestimate insulin resistance that might be attributable to schizophrenia in general, owing to these acute metabolic effects of stress (Ryan et al, 2003; Reynolds, 2006). This study also contained subjects taking concomitant medications, which have the potential to obscure the effects of individual antipsychotic medications. However, the significance of the primary result that BMI strongly predicts MinMod $S_{\text {I }}$ was not changed when subjects taking different concomitant medications were serially removed from the analysis. This study used BMI or waist circumference as an indicator of adiposity, rather than a direct measure of whole-body or regional adiposity that could provide better sensitivity to detect effects of interest. It should be noted, however, that BMI has well-established predictive validity for insulin sensitivity (Karter et al, 1996), and is a readily available measure in clinical practice with high test-retest reliability.

Although the results of this study indicate that adiposity is a significant predictor of insulin sensitivity, adiposity alone does not predict all the variance. In this study, adiposity as estimated by BMI or waist circumference explained on average approximately $33-34 \%$ of the variance in insulin sensitivity (Figure 1). Studies using FSIVGTTs in nonpsychiatric samples to determine the predictive value of BMI on insulin sensitivity, have reported that BMI explains from 23\% (Karter et al, 1996) to 45\% (Macor et al, 1997) of the variance in insulin sensitivity. Additional contributions to variance in insulin sensitivity may come from genotype (Valle et al, 1998; Lebovitz, 1999; Watanabe et al, 1999; Elbein et al, 2000; Baroni et al, 2001; McIntyre and Walker, 2002) and fitness level (Reaven, 2003).

In summary, this study confirms that adiposity is a significant predictor of insulin sensitivity during antipsychotic treatment. A decrease in insulin sensitivity is a key event in the development of physiological changes associated with the insulin resistance syndrome and the metabolic syndrome, leading to increased risk for cardiovascular disease and type 2 diabetes mellitus. Increases in adiposity that occur as a result of antipsychotic treatment should be anticipated to potentially increase insulin resistance and cardiometabolic risk as much as other causes of increased adiposity. The predictive effect of adiposity on insulin sensitivity can be readily observed using the clinically available measures of BMI and waist circumference, supporting the value of these measures in recent guidelines concerning risk management during antipsychotic therapy (American Diabetes Association, 2004).

\section{ACKNOWLEDGEMENTS}

Supported by MH63985 (JN), MH 67795 (DH), NARSAD (JN and DH), Pfizer Inc., Janssen Pharmaceutica, USPHS 5MO1 RR00036, and Washington University Clinical Nutrition Research Unit Center Grant nos. P30 DK56341 and P60-DK20579.

\section{REFERENCES}

Ader M, Pacini G, Yang YJ, Bergman RN (1985). Importance of glucose per se to intravenous glucose tolerance. Comparison of the minimal-model prediction with direct measurements. Diabetes 34: 1092-1103.

Allebeck P (1989). Schizophrenia: a life-shortening disease. Schizophr Bull 15: 81-89.

Allison DB, Fontaine KR, Heo M, Mentore JL, Cappelleri JC, Chandler LP et al (1999). The distribution of body mass index among individuals with and without schizophrenia. J Clin Psychiatry 60: 215-220.

American Diabetes Association (2004). Consensus development conference on antipsychotic drugs and obesity and diabetes. Diabetes Care 27: 596-601.

American Psychiatric Association (1994). Diagnostic and Statistical Manual of Mental Disorders, 4th edn. American Psychiatric Association: Washington, DC.

Baroni MG, Arca M, Sentinelli F, Buzzetti R, Capici F, Lovari S et al (2001). The G972R variant of the insulin receptor substrate-1 (IRS-1) gene, body fat distribution and insulin-resistance. Diabetologia 44: 367-372.

Beard JC, Bergman RN, Ward WK, Porte D (1986). The insulin sensitivity index in nondiabetic man. Correlation between clamp-derived and IVGTT-derived values. Diabetes 35: 362-369.

Bergman RN (1989). Lilly lecture 1989. Toward physiological understanding of glucose tolerance. Minimal-model approach. Diabetes 38: 1512-1527.

Bergman RN, Phillips LS, Cobelli C (1981). Physiologic evaluation of factors controlling glucose tolerance in man: measurement of insulin sensitivity and beta-cell glucose sensitivity from the response to intravenous glucose. J Clin Invest 68: 1456-1467.

Bergman RN, Prager R, Volund A, Olefsky JM (1987). Equivalence of the insulin sensitivity index in man derived by the minimal 
model method and the euglycemic glucose clamp. J Clin Invest 79: $790-800$.

Bjorntorp P, Rosmond R (2000). Neuroendocrine abnormalities in visceral obesity. Int J Obes Relat Metab Disord 24(Suppl 2): S80-S85.

Boehm G, Racoosin JA, Laughren TP, Katz R (2004). Consensus development conference on antipsychotic drugs and obesity and diabetes: response to consensus statement. Diabetes Care 27: 2088-2089; author reply 2089-2090.

Casey DE, Haupt DW, Newcomer JW, Henderson DC, Sernyak MJ, Davidson $M$ et al (2004). Antipsychotic-induced weight gain and metabolic abnormalities: implications for increased mortality in patients with schizophrenia. J Clin Psychiatry 65: 4-18.

Davidson M (2002). Risk of cardiovascular disease and sudden death in schizophrenia. J Clin Psychiatry 63(Suppl 9): 5-11.

Davidson S, Judd F, Jolley D, Hocking B, Thompson S, Hyland B (2001). Cardiovascular risk factors for people with mental illness. Aust N Z J Psychiatry 35: 196-202.

Dixon L, Postrado L, Delahanty J, Fischer PJ, Lehman A (1999). The association of medical comorbidity in schizophrenia with poor physical and mental health. J Nerv Ment Dis 187: 496-502.

Elbein SC, Wegner K, Kahn SE (2000). Reduced beta-cell compensation to the insulin resistance associated with obesity in members of caucasian familial type 2 diabetic kindreds. Diabetes Care 23: 221-227.

Graham KA, Perkins DO, Edwards LJ, Barrier Jr RC, Lieberman JA, Harp JB (2005). Effect of olanzapine on body composition and energy expenditure in adults with first-episode psychosis. Am J Psychiatry 162: 118-123.

Haffner SM, Kennedy E, Gonzalez C, Stern MP, Miettinen H (1996). A prospective analysis of the HOMA model. The Mexico City Diabetes Study. Diabetes Care 19: 1138-1141.

Harris EC, Barraclough B (1998). Excess mortality of mental disorder. Br J Psychiatry 173: 11-53.

Harris MI, Flegal KM, Cowie CC, Eberhardt MS, Goldstein DE, Little RR et al (1998). Prevalence of diabetes, impaired fasting glucose, and impaired glucose tolerance in US adults. The Third National Health and Nutrition Examination Survey, 1988-1994. Diabetes Care 21: 518-524.

Haupt DW (2006). Differential metabolic effects of antipsychotic treatments. Eur Neuropsychopharmacol 16(Suppl 3): S149-S155.

Henderson DC, Cagliero E, Copeland PM, Borba CP, Evins E, Hayden D et al (2005). Glucose metabolism in patients with schizophrenia treated with atypical antipsychotic agents: a frequently sampled intravenous glucose tolerance test and minimal model analysis. Arch Gen Psychiatry 62: 19-28.

Hermans MP, Levy JC, Morris RJ, Turner RC (1999a). Comparison of insulin sensitivity tests across a range of glucose tolerance from normal to diabetes. Diabetologia 42: 678-687.

Hermans MP, Levy JC, Morris RJ, Turner RC (1999b). Comparison of tests of beta-cell function across a range of glucose tolerance from normal to diabetes. Diabetes 48: 1779-1786.

Herran A, de Santiago A, Sandoya M, Fernandez MJ, Diez-Manrique JF, Vazquez-Barquero JL (2000). Determinants of smoking behaviour in outpatients with schizophrenia. Schizophr Res 41: 373-381.

Houseknecht KL, Robertson AS, Zavadoski W, Gibbs EM, Johnson DE, Rollema H (2007). Acute effects of atypical antipsychotics on whole-body insulin resistance in rats: implications for adverse metabolic effects. Neuropsychopharmacology 32: 289-297.

Janssen I, Heymsfield SB, Allison DB, Kotler DP, Ross R (2002). Body mass index and waist circumference independently contribute to the prediction of nonabdominal, abdominal subcutaneous, and visceral fat. Am J Clin Nutr 75: 683-688.

Karter AJ, Mayer-Davis EJ, Selby JV, D’Agostino Jr RB, Haffner SM, Sholinsky P et al (1996). Insulin sensitivity and abdominal obesity in African-American, Hispanic, and non-Hispanic white men and women. The Insulin Resistance and Atherosclerosis Study. Diabetes 45: 1547-1555.

Koh-Banerjee P, Wang Y, Hu FB, Spiegelman D, Willett WC, Rimm EB (2004). Changes in body weight and body fat distribution as risk factors for clinical diabetes in US men. Am J Epidemiol 159: 1150-1159.

Lebovitz HE (1999). Type 2 diabetes: an overview. Clin Chem 45: 1339-1345.

Lindenmayer JP, Czobor P, Volavka J, Citrome L, Sheitman B, McEvoy JP et al (2003). Changes in glucose and cholesterol levels in patients with schizophrenia treated with typical or atypical antipsychotics. Am J Psychiatry 160: 290-296.

Macor C, Ruggeri A, Mazzonetto P, Federspil G, Cobelli C, Vettor R (1997). Visceral adipose tissue impairs insulin secretion and insulin sensitivity but not energy expenditure in obesity. Metabolism 46: 123-129.

Matthews DR, Hosker JP, Rudenski AS, Naylor BA, Treacher DF, Turner RC (1985). Homeostasis model assessment: insulin resistance and beta-cell function from fasting plasma glucose and insulin concentrations in man. Diabetologia 28: 412-419.

Mayer-Davis EJ, Monaco JH, Hoen HM, Carmichael S, Vitolins MZ, Rewers MJ et al (1997). Dietary fat and insulin sensitivity in a triethnic population: the role of obesity. The Insulin Resistance Atherosclerosis Study (IRAS) [see comments]. Am J Clin Nutr 65: 79-87.

McIntyre EA, Walker M (2002). Genetics of type 2 diabetes and insulin resistance: knowledge from human studies. Clin Endocrinol (Oxf) 57: 303-311.

McLaughlin T, Abbasi F, Cheal K, Chu J, Lamendola C, Reaven G (2003). Use of metabolic markers to identify overweight individuals who are insulin resistant. Ann Intern Med 139: 802-809.

Meyer JM (2002). A retrospective comparison of weight, lipid, and glucose changes between risperidone- and olanzapine-treated inpatients: metabolic outcomes after 1 year. J Clin Psychiatry 63: 425-433.

National Cholesterol Education Program (2002). Third Report of the National Cholesterol Education Program (NCEP) Expert Panel on Detection, Evaluation, and Treatment of High Blood Cholesterol in Adults (Adult Treatment Panel III) final report. Circulation 106: 3143-3421.

National Institutes of Health (2000). The practical guideidentification, evaluation, and treatment of overweight and obesity in adults. NIH Publication Number 00-4084.

Newcomer JW (2005). Second-generation (atypical) antipsychotics and metabolic effects: a comprehensive literature review. CNS Drugs 19(Suppl 1): 1-93.

Newcomer JW, Haupt DW, Fucetola R, Melson AK, Schweiger JA, Cooper BP et al (2002). Abnormalities in glucose regulation during antipsychotic treatment of schizophrenia. Arch Gen Psychiatry 59: 337-345.

Nurnberger JIJ, Blehar MC, Kaufmann CA, York-Cooler C, Simpson SG, Harkavy-Friedman J et al (1994). Diagnostic interview for genetic studies. Rationale, unique features, and training. NIMH Genetics Initiative. Arch Gen Psychiatry 51: 849-859 discussion 863-864.

Osby U, Correia N, Brandt L, Ekbom A, Sparen P (2000). Mortality and causes of death in schizophrenia in Stockholm county, Sweden. Schizophr Res 45: 21-28.

Overall JE (1974). A brief psychiatric rating scale in psychopharmacology research. Psychological Measurements in Psychopharmacology, Modern Problems in Pharmacopsychiatry. Karger: Basel. pp 67-78.

Peiris AN, Sothmann MS, Hoffmann RG, Hennes MI, Wilson CR, Gustafson $\mathrm{AB}$ et al (1989). Adiposity, fat distribution, and cardiovascular risk. Ann Intern Med 110: 867-872.

Reaven G (2003). Age and glucose intolerance: effect of fitness and fatness. Diabetes Care 26: 539-540. 
Reaven GM (2005). The metabolic syndrome: requiescat in pace. Clin Chem 51: 931-938.

Resnick HE, Valsania P, Halter JB, Lin X (1998). Differential effects of BMI on diabetes risk among black and white Americans. Diabetes Care 21: 1828-1835.

Reynolds GP (2006). Metabolic syndrome and schizophrenia. Br J Psychiatry 188: 86; author reply 86-87.

Ryan MC, Collins P, Thakore JH (2003). Impaired fasting glucose tolerance in first-episode, drug-naive patients with schizophrenia. Am J Psychiatry 160: 284-289.

Simpson GM, Glick ID, Weiden PJ, Romano SJ, Siu CO (2004). Randomized, controlled, double-blind multicenter comparison of the efficacy and tolerability of ziprasidone and olanzapine in acutely ill inpatients with schizophrenia or schizoaffective disorder. Am J Psychiatry 161: 1837-1847.

Steil GM, Volund A, Kahn SE, Bergman RN (1993). Reduced sample number for calculation of insulin sensitivity and glucose effectiveness from the minimal model. Suitability for use in population studies. Diabetes 42: 250-256.
Valle T, Tuomilehto J, Bergman RN, Ghosh S, Hauser ER, Eriksson J et al (1998). Mapping genes for NIDDM. Design of the FinlandUnited States Investigation of NIDDM Genetics (FUSION) Study. Diabetes Care 21: 949-958.

Watanabe RM, Valle T, Hauser ER, Ghosh S, Eriksson J, Kohtamaki K et al (1999). Familiality of quantitative metabolic traits in Finnish families with non-insulin-dependent diabetes mellitus. Finland-United States Investigation of NIDDM Genetics (FUSION) Study investigators. Hum Hered 49: 159-168.

Welch S, Gebhart SS, Bergman RN, Phillips LS (1990). Minimal model analysis of intravenous glucose tolerance test-derived insulin sensitivity in diabetic subjects. J Clin Endocrinol Metab 71: 1508-1518.

World Health Organization (1985). Diabetes Mellitus: Report of a WHO Study Group. World Health Organization: Geneva.

Zhang ZJ, Yao ZJ, Liu W, Fang Q, Reynolds GP (2004). Effects of antipsychotics on fat deposition and changes in leptin and insulin levels. Magnetic resonance imaging study of previously untreated people with schizophrenia. Br J Psychiatry 184: 58-62. 